\title{
Mulheres e professoras: repercussões da dupla jornada nas condições de vida e no trabalho docente ${ }^{1}$
}

\section{Women and teachers: repercussions of double duty on life conditions and on teaching work}

\author{
Marli Lúcia Tonatto Zibetti ${ }^{2}$ \\ Sidnéia Ribeiro Pereira ${ }^{3}$
}

\begin{abstract}
RESUMO
De uma perspectiva dos estudos de gênero, esta pesquisa, de abordagem qualitativa, discute as condições de vida e trabalho de mulheres que atuam na docência em educação infantil e nas séries iniciais do ensino fundamental em três redes municipais do interior do estado de Rondônia. Os resultados indicam que as inadequadas condições de trabalho nas escolas, quando somadas à desigual divisão das atribuições domésticas e à ausência de serviços públicos de atendimento às mães trabalhadoras, repercutem de maneira negativa nas condições de vida e na qualidade do trabalho docente. Palavras-chave: gênero; trabalho doméstico; trabalho docente; dupla jornada.
\end{abstract}

\begin{abstract}
From a gender perspective, this study, with qualitative approach, discusses women's life and work conditions when they work for children education at public schools concerning the first grades of elementary education in the interior of Rondonia State, Brazil. The results reveal bad conditions of life and work for these women who, besides being teachers, have to take care of their houses and do not have social assistance. Being women, housewives and teachers bring negative consequences to their lives and their job as educators. Keywords: gender; house holding; teaching work; double duty.
\end{abstract} (CNPq).

1 Pesquisa Financiada pelo Conselho Nacional de Desenvolvimento Científico e Tecnológico

2 Doutora em Psicologia pela Universidade de São Paulo; Professora do Curso de Psicologia da Universidade Federal de Rondônia (UNIR), Brasil. E-mail: marlizibetti@yahoo.com.br.

3 Graduada em Pedagogia pela Universidade Federal de Rondônia; Professora da Rede Estadual de Ensino em Rolim de Moura, Rondônia, Brasil. 


\section{Introdução}

A sociedade brasileira tem discutido enfaticamente a necessidade de melhorar a qualidade do ensino, para que crianças e jovens tenham acesso aos conhecimentos socialmente produzidos. Entretanto, a inadequada e insuficiente aplicação dos recursos financeiros tem transformado o discurso sobre melhoria da educação em retórica na voz dos dirigentes e gerado descrédito entre profissionais e usuários das redes públicas de ensino.

Historicamente, a ênfase nas discussões sobre melhoria da qualidade tem recaído, em alguns momentos, sobre a incapacidade da clientela de classes populares e, em outros, sobre a má formação dos professores e professoras. Por discordarmos dessas análises, defendemos que é necessário ampliar o olhar sobre a questão, inserindo nas discussões sobre a qualidade do ensino as condições de trabalho existentes nas escolas, inclusive da perspectiva dos estudos de gênero.

O presente trabalho discute alguns aspectos de uma pesquisa desenvolvida em três municípios do interior do estado de Rondônia envolvendo professoras das redes municipais de ensino e teve como objetivo investigar as implicações da condição feminina no trabalho docente. Neste texto, interessa-nos discutir como a ausência de horário destinado ao planejamento e preparação de materiais e atividades dentro da jornada de trabalho gera atribuições extras às professoras, tarefas que se somam às responsabilidades domésticas e repercutem de forma negativa sobre a qualidade de vida e do trabalho docente.

Julgamos que o presente estudo contribui para ampliar o conhecimento sobre a docência em municípios do interior do Brasil e, como afirma o documento da UNESCO sobre o perfil dos/as professores/as brasileiros/as:

\footnotetext{
Aprofundar o conhecimento sobre quem são esses professores constitui condição essencial para que se possam tornar efetivas as iniciativas voltadas à sua valorização e à possibilidade real de que venham corresponder às expectativas neles depositadas, sobretudo em um país como o Brasil, onde a questão da educação reveste-se de absoluta importância e onde a legislação confere à formação do docente caráter fundante da política educacional. (UNESCO, 2004, p. 18-19).
}

Considerando que a maior parte das políticas públicas e as iniciativas de valorização e de formação docente têm ignorado a composição majoritariamente 
feminina do magistério, principalmente na educação infantil e anos iniciais do ensino fundamental, estudos como este assumem relevância.

Apresentamos, inicialmente, uma discussão sobre o trabalho doméstico como responsabilidade feminina, mesmo quando as mulheres estão formalmente inseridas no mercado de trabalho. Em seguida descrevemos, brevemente, a pesquisa da qual foram extraídos os dados para, com base nesse material, evidenciar a realidade das professoras que se dividem entre o trabalho profissional, os cuidados com a casa, os filhos e as demandas dos cursos de formação.

\section{Trabalho doméstico e trabalho profissional: a sobrecarga feminina}

De acordo com Scott (1995), uma das características do conceito de gênero é o de ser relacional, implicando uma análise que envolva ao mesmo tempo homens e mulheres. Assim, a condição das mulheres nas sociedades ocidentais precisa ser analisada tendo-se em mente as relações de gênero hierárquicas que predominam e que se expressam em desigualdade nas posições ocupadas, de acordo com o sexo, tanto na esfera da produção quanto no âmbito das relações familiares.

A origem do trabalho doméstico remonta ao Brasil escravagista. Era praticado de maneira gratuita ou semigratuita por mulheres livres ou escravas. Mais tarde, foi atribuído às mocinhas como retribuição às famílias que as acolhiam em forma de apadrinhamento, prática que se manteve até meados dos anos 1950. Conforme Kosminsky e Santana (2006, p. 1) "[...] em nossa sociedade é um fato histórico e cultural a incumbência dessa atividade econômica a terceiros, principalmente às jovens mulheres não brancas, pobres e de origem rural, pessoas cuja força de trabalho é sub-valorizada." A entrada de muitas adolescentes pobres no mundo do trabalho ocorre via emprego doméstico, uma vez que desde a infância são submetidas a uma espécie de treinamento especial para o exercício destas funções, fornecido pelas mães, avós, tias ou qualquer outra figura feminina próxima.

Kosminsky e Santana (2006) veem, neste encaminhamento, a expressão da organização patriarcal da família brasileira na qual ao homem é atribuído o papel de provedor, guardião do lar e à mulher a responsabilidade pelo cuidado com a casa e os membros da família. E, na ausência da dona da casa, atividades como limpar, lavar, passar, cozinhar e tomar conta das crianças menores são exercidas por meninas. Esta situação está mais presente entre as camadas populares, pois em outras camadas sociais, as mesmas tarefas são atribuições de outrem (mãe ou empregada) e as/os jovens dedicam-se a atividades de qualificação para uma profissão futura. 
Por não resultar em mercadoria, o trabalho ou o serviço doméstico desenvolvido em favor do próprio grupo familiar é entendido como uma forma de respeito, reciprocidade e obediência, portanto, pouco valorizado, mesmo quando contribui para liberar alguns membros da família para outras atividades remuneradas.

A divisão entre o masculino e o feminino organizou-se, segundo Bourdieu (1995, p. 156), em torno da oposição entre o interior e o exterior, ou seja, entre a casa, com a educação das crianças, e o mundo do trabalho. Esta forma canônica, segundo o autor, fundada pela burguesia, estabelece a divisão entre o universo da empresa, voltado para o lucro e o universo da casa, voltado à reprodução biológica. "[...] com a entrada das mulheres no mercado de trabalho, a fronteira deslocou-se sem se anular, pois que setores protegidos constituíram-se no interior do mundo do trabalho." Para o autor, a dominação masculina estende-se aos próprios corpos humanos que são adestrados por meio de práticas e rituais coletivos que produzem corpos sexuados e sexuantes, cuja identidade social é baseada nesse mundo simbolicamente construído.

De acordo com pesquisa de Sorj (2004), às mulheres são destinadas as piores formas de inserção no mercado de trabalho. Os rendimentos são inferiores aos dos homens e a qualidade da ocupação normalmente é menor. A maior parte das mulheres cônjuges está ocupada em postos de trabalho informais, sem carteira assinada, ou está em empregos sem remuneração ou para autoconsumo. E "um grande número de mulheres cônjuges também se ocupa do trabalho doméstico". (SORJ, 2004, p. 21).

A análise da jornada de trabalho permite identificar o peso que as responsabilidades familiares têm para as mulheres, pois enquanto as jornadas de trabalho dos homens são mais elevadas do que as delas em todos os tipos de famílias, para as mulheres essas variam conforme a presença ou não de dependentes e de parentes que auxiliem nos cuidados com os filhos. Nas famílias em que as mulheres cônjuges têm filhos dependentes e têm parentes no mesmo domicílio, a jornada de trabalho remunerado aumenta em uma hora em relação àquelas que não possuem este apoio. Outro dado importante trazido pela pesquisa de Sorj $(2004$, p. 27) é:

[...] as mulheres que se sobressaem no mercado de trabalho, ou seja, que conseguem obter um nível de renda mais alto e se inserir em empregos melhores (quase 60\% delas são empregadas com carteira de trabalho assinada, funcionárias públicas ou empregadoras), estão sozinhas. Não formaram ainda uma família, ou já formaram uma família e agora estão sozinhas, separadas e com filhos já adultos que vivem em outros domicílios, constituindo, possivelmente uma outra família. 
Utilizando dados do survey realizado pela Fundação Perseu Abramo em 2001, Venturi e Recamán (2005) explicam que em 96\% dos domicílios pesquisados a principal responsável pelas tarefas domésticas era uma mulher. Além disso, em $49 \%$ dos casos em que havia outra pessoa para auxiliar nestas tarefas, tratava-se também de uma mulher. Ou seja, ainda há uma enorme distância entre a igualdade defendida pelas mulheres e também pela sociedade e as práticas sociais em curso nos ambientes domésticos, conforme evidenciam os dados:

Indagadas sobre o tempo dedicado aos cuidados da casa e da família na semana que antecedeu a coleta dos dados, as entrevistadas informaram uma jornada semanal média de 39 horas e 36 minutos (23h52 nas tarefas de limpar a casa, cozinhar, lavar e passar roupas; $13 \mathrm{~h} 57$ no cuidado de filhos e $1 \mathrm{~h} 47$ no cuidado de idosos e doentes). A média cai para $27 \mathrm{~h} 42$ entre as mulheres não casadas, e sobe para $48 \mathrm{~h} 30$, entre as que moram com cônjuge contra, segundo estas, apenas $5 \mathrm{~h} 36$ de seus parceiros (VENTURI; RECAMÁN, 2005, p. 4)

Entretanto, como todo fenômeno de opressão, sua manutenção também está relacionada com a internalização de valores e práticas dominantes por parte dos/as oprimidos/as. Desta forma, mesmo denunciando a exploração vivida no mundo doméstico, muitas mulheres compartilham e reproduzem opiniões hegemônicas na sociedade da qual fazem parte.

O trabalho de Kosminsky e Santana (2006), voltado para a investigação do trabalho doméstico desenvolvido por jovens entre 10 e 17 anos, evidencia que o diferencial nas relações de gênero não aparece unicamente na execução de tarefas domésticas, mas aponta também para a continuidade desta situação por meio da manutenção de estereótipos de gênero na educação de meninos e meninas.

A opinião dos pais e dos patrões entrevistados sobre a possibilidade dos rapazes exercerem o labor doméstico registra a continuidade da mentalidade da casa como o lugar da mulher e da pressão social para que os meninos desempenhem ações ditas masculinas, atribuindo-lhes um papel a ser seguido e qual a identidade que deve ser construída. Com exceção de uma mãe, todas as demais expressam, por meio de interjeições, que a idéia do menino exercer o labor doméstico é espantosa. Metade das 
patroas entende que os homens são incapacitados para o labor doméstico, somente uma admite a possibilidade deles conseguirem realizar algumas tarefas, mas com ressalvas. (KOSMINSKY; SANTANA, 2006, p. 9)

Para Bourdieu (1995), a mudança de mentalidades e práticas sociais depende não só de mudanças econômicas, mas também da mudança de estruturas mentais tanto do sexo dominado, quanto do sexo dominante e só terá início quando as pessoas se derem conta da situação de dominação e buscarem meios para subvertê-la.

Segundo Marcondes et al. (2003, p. 93), mesmo com o ingresso das mulheres no mercado de trabalho, o valor de sua atuação continua associado ao universo subalternizado da reprodução do mundo doméstico. "Seu trabalho e sua identidade como trabalhadoras continuam a ser de mulheres que, de certa forma, 'não deveriam estar ali', pois seu lugar permanece referido ao da casa, ao da maternidade e ao do cuidar dos outros." (grifos dos autores).

Para Araújo et al. (2006), parece haver consenso nos estudos preocupados em articular gênero, trabalho e saúde de que é necessário avaliar conjuntamente os aspectos do trabalho profissional e do trabalho doméstico para que se possa produzir conhecimentos que considerem a realidade das mulheres trabalhadoras. As investigações voltadas para estas temáticas devem levar em conta o tipo de atividades e ocupações das mulheres e suas características, avaliando-se a carga total de trabalho, considerando-se também as atribuições e responsabilidades na família e no trabalho.

A pesquisa de Araújo et al. (2006), que envolveu professores/as de escolas públicas de Salvador, evidencia, também neste tipo de ocupação, a sobrecarga das mulheres com o trabalho doméstico:

A responsabilidade feminina pelo trabalho doméstico mostrou-se relevante, ainda uma atribuição mais das professoras do que dos professores, mesmo dado o processo de profissionalização destas mulheres. A dupla jornada de trabalho, profissional e doméstico, foi, de fato, uma realidade para as mulheres estudadas. Vale lembrar que as mulheres apresentaram menores níveis de qualificação formal, sendo a necessidade de realizar a dupla jornada de trabalho um possível obstáculo ao avanço profissional. (ARAÚJO et al., 2006, p. 1127) 
Ao analisar a problemática da saúde docente de uma perspectiva de gênero os/as autores/as (ARAÚJO et al., 2006, p. 1120) afirmam que a sobrecarga psicológica, fadiga física ou burnout, bem como a falta de tempo para o lazer, descanso, sono e alimentação são algumas das repercussões da dupla jornada sobre a saúde.

A docência tem sido caracterizada como uma profissão extremamente desgastante, cuja execução é agravada pelas condições de trabalho tais como jornadas exaustivas, salários insuficientes e demandas que extrapolam o ambiente profissional. Estas condições têm contribuído para o adoecimento do corpo docente, temática estudada por vários pesquisadores como Esteve (1999), Siqueira e Ferreira (2003) e Codo (2006).

Entretanto, pouca ênfase tem sido dada à questão da sobrecarga feminina com o trabalho doméstico, acentuada pelas demandas do trabalho docente que, pela falta de tempo destinado a essas tarefas no ambiente escolar, invade a vida privada. Nossa pesquisa evidencia o quanto estas duas questões estão relacionadas e aponta algumas repercussões desta situação no trabalho docente.

\section{A pesquisa}

Por meio de análise documental dos Planos de Carreira, Cargos e remuneração, entrevistas com técnicas das secretarias de educação e realização de encontros de Grupo Focal com as professoras, a investigação analisou as condições de trabalho nos municípios de Rolim de Moura, Alta Floresta D’Oeste e Nova Brasilândia D'Oeste, todos localizados no interior do Estado de Rondônia.

Neste texto, analisaremos os depoimentos das professoras, obtidos por meio dos encontros de grupo focal que, segundo Gatti (2005), podem se caracterizar como instrumento importante na compreensão dos processos de construção da realidade por determinados grupos sociais. As opiniões das docentes nos permitem problematizar as relações entre as demandas do trabalho profissional, somadas às demandas do trabalho doméstico e às repercussões que esta sobrecarga ocasiona na vida e no trabalho das participantes da pesquisa.

Colaboraram com esta etapa da pesquisa 80 professoras com idades entre 22 e 62 anos: 56 delas casadas, 13 solteiras, oito divorciadas e três viúvas. Sete não têm filhos; 30 têm um filho, 27 têm dois filhos e 16 têm mais de dois filhos.

O tempo de trabalho em educação das professoras ouvidas oscila entre $2 \mathrm{e}$ 30 anos. E, das 80 participantes, 62 trabalham 40 horas, 15 trabalham 25 horas e apenas três têm contratos de 20 horas. 
Em relação à formação, 45 delas cursaram magistério em escolas de curso regular e 35 em cursos especiais oferecidos em regime supletivo (LOGUS, FÊNIX e Pró-formação). Quanto à formação em nível superior, 27 concluíram o curso de Pedagogia. As demais estão cursando Pedagogia ou Normal Superior, 98\% no sistema de ensino a distância. ${ }^{4}$

Foram realizados nove encontros de Grupo Focal, três em cada município, com a participação de 8 a 9 professoras em cada sessão. Os encontros foram coordenados por uma mediadora, com a colaboração de duas auxiliares de pesquisa que realizaram as anotações necessárias para complementar as gravações.

\section{"A gente trabalha em casa e também leva trabalho da escola para casa"}

$\mathrm{O}$ ano passado eu peguei uma $1^{\mathrm{a}}$ série de manhã e uma $2^{\mathrm{a}}$ à tarde. Eu tinha que me desdobrar para planejar e não acho assim o salário suficiente para a gente pagar uma pessoa para ajuda, entendeu? Então pesou demais. Eu acho assim que o salário não está bom. Eu acho que a nossa remuneração tinha que ter assim um complemento a mais levando por esse ponto, entendeu? Porque a gente trabalha em casa e também leva trabalho da escola para casa. (Professora das séries iniciais - $7 / \mathrm{NB}^{5}$ )

O depoimento da professora, destacado na epígrafe, aponta para os vários problemas enfrentados pelas/os profissionais que atuam nas três redes municipais de ensino, conforme dados obtidos pela pesquisa: baixos salários, carga horária exaustiva e ausência de horário destinado ao planejamento dentro da jornada de trabalho, obrigando as professoras a levarem atividades da escola para casa.

4 A dificuldade de acesso à formação é uma característica relevante neste grupo, pois indica o esforço que estas mulheres têm empreendido para obter a escolarização exigida ao exercício da função docente. Muitas delas, cujo acesso ao ensino médio foi obtido em cursos semipresenciais, devido à dificuldade de acesso aos centros urbanos em que este era oferecido na modalidade regular, novamente só têm acesso à graduação no sistema a distância e o que é mais grave ainda, em cursos pagos, os quais obrigam as professoras a gastarem parte dos diminutos salários com a própria formação.

5 Utilizaremos as iniciais para designar os municípios em que atuam as professoras: NB para Nova Brasilândia, AF para Alta Floresta e RM para Rolim de Moura. 
As professoras dos municípios pesquisados com contratos de 40 horas são responsáveis por duas turmas de alunos trabalhando, portanto, 8 horas diárias em sala de aula. Aquelas que são contratadas por 20 e 25 horas trabalham 4 horas em sala de aula. De acordo com os Planos de Carreira, Cargos e Remuneração dos três municípios, $20 \%$ da carga horária de contrato devem ser destinados ao planejamento e preparação das aulas. Entretanto, as Secretarias de Educação não têm conseguido garantir este direito, fazendo diferentes "arranjos" para minimizar o problema.

Uma das práticas mais adotadas tem sido a contratação de professoras "rodízio" que substituem, a cada dia, uma professora diferente, enquanto a titular elabora seu planejamento. Entretanto, além de considerarem este tempo insuficiente para a realização de todas as atividades necessárias à preparação das aulas, as docentes afirmam que este sistema não tem sido eficiente, visto que nos casos de falta de professoras, a profissional de rodízio substitui aquela que faltou, deixando de liberar a titular que deveria planejar naquele dia.

Em outras situações, como é o caso das escolas multisseriadas da zona rural, as secretarias remuneram, além da carga horária regular, as horas destinadas ao planejamento, o que do ponto de vista financeiro significa uma recompensa, mas em relação ao tempo, acentua a sobrecarga de atividades a serem desenvolvidas no ambiente doméstico.

Assim, nos três municípios investigados, além do salário, a dupla jornada em sala de aula e a ausência ou insuficiência do horário disponível para planejamento e preparação de atividades dentro da jornada, comparecem como as principais fontes de insatisfação na opinião das entrevistadas.

[...] quem ganha 40 horas tem que ficar em de sala de aula, mas você não tem, na verdade, nem o seu tempo para planejar as suas atividades então você tem que aproveitar ali um intervalinho na hora do recreio [...]. (Professora de Educação Infantil - 3/AF) [...] nós estamos no dia 16 de maio e eu não tive nenhum dia de planejamento no período da tarde; com o período da manhã nós tivemos algum dia de semana para planejar. Pode até contar e eu chamava de "meu dia de princesa", porque nós não estamos tendo [horário para] planejamento e a gente tem que planejar em casa. (Professora das Séries Iniciais - 14/RM)

A docência com crianças pequenas caracteriza-se como uma atividade extremamente desgastante, pois exige atenção constante, paciência e resistência física. As professoras são unânimes em descrever que se sentem cansadas após 
uma jornada de oito horas em sala de aula. Além disso, o tempo que teriam para um pequeno descanso, entre uma jornada e outra, é ocupado com o planejamento de atividades e a preparação de materiais necessários à aula. Como este tempo não é suficiente, as professoras são obrigadas a realizar em casa, parte do trabalho que deveria ser feito na escola.

Esta situação, além de influenciar a qualidade do ensino oferecido às crianças, também é responsável pela deterioração na qualidade de vida das profissionais que, ao lado das tarefas domésticas e familiares, ainda precisam dedicar boa parcela do tempo às tarefas escolares.

A ausência de tempo para cumprir as obrigações profissionais dentro da jornada de trabalho e os baixos salários que impedem a contratação de ajudantes para as tarefas domésticas caracterizam a vida das participantes da pesquisa, pois das 80 professoras ouvidas, apenas duas (solteiras) afirmaram não assumirem responsabilidades diretas sobre o trabalho doméstico, contribuindo apenas de maneira esporádica com essas tarefas. Cinco afirmaram contar com ajudante remunerada três vezes por semana. As demais, ou contam com ajuda de familiares que moram na mesma casa (mães, filhas, sobrinhas, marido), ou assumem sozinhas as atribuições com o trabalho doméstico.

[...] tem minha mãe perto que ajuda muito, pois pagar empregada eu não posso. O dia que eu fico em casa, faço o trabalho de casa, tiro o sábado pra ir pra faculdade. (Professora das Séries Iniciais - 7/AF)

[...] eu tenho uma menina com dezesseis anos que estuda à tarde e ela faz um pouco do serviço. Quando eu chego da escola faço o que ela não fez; lavo roupa no sábado. (Professora das Séries Iniciais - 12/RM)

Diariamente, a única coisa que eu faço lá em casa é comida. [...] e daí o quê acontece no final de semana? É o dia inteiro lavando, passando, esticando, guardando. (Professora de Educação Infantil - 6/NB) Eu divido com minha família, meu esposo, meus filhos. Ainda bem que eu tenho um esposo que me ajuda muito! Meus meninos, tenho um com 16 anos e um com 13. Hoje tenho uma sobrinha em casa... ela tá me ajudando! Mas a minha casa, se eu for pagar alguém, não tem como pagar. Então as tarefas de casa eu divido! (Professora das Séries Iniciais - 13/RM)

Os depoimentos das professoras, que são semelhantes nos três municípios, confirmam que o trabalho doméstico tem recaído sobre as mulheres. Quando 
não são as donas de casa, são as filhas, ou parentes que moram na mesma casa, as principais, quando não as únicas, responsáveis por essas tarefas. Além disso, as afirmações das docentes evidenciam uma jornada extremamente atribulada, com tarefas acumuladas para os finais de semana.

Considerando que uma grande parte de nossa amostra ainda está cursando graduação, o acúmulo de atribuições tem se caracterizado como sobrecarga que lhes rouba horas de descanso, seja à noite ou nos finais de semana, conforme descrevem as profissionais, cujos depoimentos destacamos:

[...] eu chego de noite, largo a moto pra lá, desamarro a bolsa, e já vou lavando roupa. Meu marido fala: "Oh! Meu Deus, perdi a mulher!" [...] no sábado tem que ir para a faculdade. Tem dia que eu vou pra faculdade sem almoçar, porque tem que colocar a roupa no varal, vou dar uma limpadinha na casa, vou limpar o banheiro.[...]. É muito corrido. Muito, muito, muito! Meu Deus do céu, tem hora que dá vontade de desistir. (Professora Séries Iniciais-1/AF)

[...] cinco horas já levanto para trabalhar quando não levanto mais cedo. E vou dormir umas dez, onze horas. À noite eu faço janta, faço tudo à noite, porque eu levanto cinco horas pra não levantar um pouquinho mais cedo [...]. Faço faculdade no sábado, aí só tem domingo para mexer com trabalho da faculdade. (Professora Séries Iniciais-1/NB)

Eu tenho uma filha de 10 anos. Também passo o dia inteiro na escola e à noite vou para a faculdade. Ainda cuido da minha casa e não tenho ninguém que me ajude. Só ela [a filha] mesmo lava uma loucinha, arruma a cama. É tudo por minha conta: é pagar contas, ir ao mercado, tudo! (Professora Educação Infantil-5/AF)

De acordo com Vasques-Menezes, Codo e Medeiros (2006, p. 257), a dupla jornada dos trabalhadores e trabalhadoras em educação não mais está restrita às mulheres. "Homens hoje já sentem na pele o que é isso e de forma crescente vêm dividindo com as mulheres as responsabilidades e os afazeres do lar." Embora algumas professoras de nossa pesquisa tenham afirmado a participação dos companheiros nas tarefas domésticas, fica evidente que esta se caracteriza como uma contribuição, que está mais presente na responsabilidade com os filhos, nas compras de supermercado e no preparo das refeições, pois em nenhum dos depoimentos são mencionados homens cuidando da faxina ou responsabilizando-se pela roupa, por exemplo. 
Esta sobrecarga evidencia aspectos culturais que se mantêm nas relações familiares, os quais levam as mulheres a assumirem as mesmas demandas que lhes eram atribuídas antes de ingressarem no mercado de trabalho. Mas também é consequência dos baixos salários recebidos pela categoria, pois enquanto outros/ as profissionais mais bem remunerados/as encontram tempo livre para a família e o lazer por meio da contratação de mão de obra doméstica, as professoras não têm condições de fazer o mesmo.

A diferenciação da força de trabalho entre homens e mulheres, construída historicamente desde a antiguidade, permanece. Ou seja, até bem pouco tempo atrás o lugar aceito para a mulher era cuidando da casa, dos filhos e do marido. E, embora este quadro venha mudando rapidamente como resultado da luta feminista e das necessidades econômicas com as quais se deparam as famílias, a imagem da mulher como "cuidadora", responsável pelo bem estar dos filhos e do marido em relação à limpeza e arrumação da casa, alimentação e saúde, permanece no imaginário de todos, inclusive das próprias mulheres.

Assim elas se veem divididas entre as demandas dos afazeres domésticos, do cuidado e atenção para os filhos e as exigências do trabalho. E, conforme afirmam Vasques-Menezes, Codo e Medeiros (2006, p. 257),"No caso da existência do conflito entre trabalho e família, onde o trabalhador sente-se roubado de um tempo que poderia estar dedicando à família, percebe-se um aumento significativo dos fatores de exaustão emocional e despersonalização."

Pode-se afirmar, portanto, que a partir do momento em que estas profissionais não contam com tempo dentro da jornada de trabalho para o planejamento das aulas, preparação de materiais didáticos ou correção de atividades dos alunos, o cotidiano familiar fica ainda mais prejudicado, exigindo delas um esforço maior.

Além disso, no contexto em que estão inseridas, em que o tempo disponível é tão exíguo e os cursos de graduação a distância reduzem-se a um encontro semanal, torna-se importante questionar a qualidade da formação realizada nessas condições. De acordo com Maués (2003), o Brasil, em sintonia com organismos internacionais que defendem a necessidade de colocar os professores no centro das reformas educacionais, propôs a formação docente em nível superior como condição para o êxito deste tipo de política. Entretanto, o que tem ocorrido é a flexibilização e o aligeiramento em relação à duração, aos conteúdos e ao locus desta formação, sem garantir o êxito das proposições iniciais de elevar a qualidade da formação docente.

O cuidado com os filhos pequenos também tem sido historicamente responsabilidade feminina e esta situação parece não ter sofrido muitas alterações com a entrada das mulheres no mercado de trabalho. Entre as 80 professoras ouvidas, poucas afirmaram pagar babás e uma informou que seu filho fica na creche. Um 
grande número deixa os filhos e filhas aos cuidados de familiares (sobrinhas, avós ou filhas mais velhas). E quatro professoras levam os filhos consigo para o trabalho. Esta é uma estratégia adotada para manter os filhos por perto, matriculando-os na mesma escola em que atuam.

No meu caso eu tive duas filhas trabalhando, dando aula. Quando elas eram pequenas eu sofri muito. Eu contei muito com a ajuda da minha mãe. Elas ficavam com minha mãe, até a mais velha começar a crescer um pouquinho e começar a ajudar. Agora ela está com 13 anos e já assumiu a casa também. (Professora de Séries iniciais $-5 / \mathrm{AF}$ )

Nunca deu pra eu dar $\mathrm{R} \$ 50,00$ pra alguém ficar com ela. Então eu vinha pra escola de manhã, ela estudava de manhã. À tarde ela vinha comigo na escola e à noite ela ia comigo pra faculdade. Então, eu fui pra psicóloga, ela foi também, porque eu estava sobrecarregando ela. Por falta de recursos pra pagar alguém pra ficar com ela, eu tinha que trazê-la junto comigo, pra minha rotina. Então ela não estava sendo criança, porque tinha que acompanhar a mãe. (Professora de Educação Infantil - 2/RM) [...] eu tenho meu filho de sete aninhos. Matriculei ele na mesma escola que eu trabalho. Cinco horas da manhã chamo meu filho. Ele acorda, toma banho e vai comigo pra escola polo ${ }^{6}$ e passamos o dia. Quando dá sono, coloco o colchãozinho e ele dorme. Não tem outro jeito: como eu vou deixar ele solto, no meio da rua? Minha mãe cuidava dele, mas agora eu perdi a minha mãe. (Professora Séries Iniciais - 1/NB)

Conforme aponta a pesquisa de Sorj (2004), as professoras de nossa amostra também indicam que o cuidado com os filhos tem sido tarefa eminentemente feminina. Os fragmentos destacados são amostras dos diferentes arranjos criados pelas professoras para garantir o cuidado dos filhos enquanto trabalham: ora são as mães, ora são as filhas mais velhas, ou parentes próximas que cuidam das crianças. Ou então, em alguns casos, as crianças são submetidas ao horário das trabalhadoras, deixando de ter uma rotina infantil para submeter-se à rotina das mães.

6 A polarização da educação no campo consiste em um movimento que tem como objetivo extinguir as escolas unidocentes por meio da implantação de escolas em regiões denominadas polo, para as quais são transportadas as crianças e jovens dos locais mais próximos. Nestas escolas as professoras também deslocam-se por meio do transporte escolar e permanecem no local o dia todo. 
A ausência de serviços públicos de apoio às mulheres trabalhadoras, creches e instituições que atendam às crianças em horário extra-escolar, penaliza tanto as professoras quanto seus filhos e filhas. E da mesma forma que as atribuições escolares invadem o espaço familiar, aqui vemos o oposto: as demandas familiares invadirem o espaço profissional.

Os fragmentos das discussões travadas nos encontros de Grupo Focal com professoras de Educação Infantil nos municípios de Rolim de Moura e Alta Floresta revelam as formas como estas profissionais decidiram enfrentar a sobrecarga decorrente da ausência de horário para planejamento dentro da jornada de trabalho:

No ano passado, eu sofri uma depressão [...] eu não conseguia vir trabalhar mais. Eu não tava dando conta: faculdade, trabalho, filho, casa, meu Deus! Eu não tava dando conta, aí eu falei: "Este ano eu vou dar conta do meu trabalho na escola, eu não vou levar um papel pra cortar em casa, não levo!" Se eu tiver que fazer alguma coisa será em sala de aula, porque têm que te dar reconhecimento. A gente tem direito de planejar. [...]. Então esse ano foi assim, sem um papel pra fazer em casa, tudo que eu precisei fazer foi em sala de aula. Como elas falaram, eu dava uma massinha para as crianças e rabiscava um diário, um caderno, sabe? (Professora Educação Infantil-2/RM) Eu também levava muita coisa pra casa, mas depois que a minha segunda filha nasceu, eu falei: "Não levo mais nada! Porque o meu primeiro filho foi muito prejudicado por causa disso. $\mathrm{Eu}$ estudava... a partir do ano passado eu não levei mais nada, não levei! Eu faço na hora do almoço, nem que eu tenha que estar na escola na hora do almoço. Dou um jeito em sala de aula, mas não levo pra casa porque a minha filha tá com um aninho, já trabalho o dia todo. A hora que eu tenho pra ela é à noite e eu vou levar trabalho pra fazer em casa? Não levo! Fica lá na escola. Porque a gente tem a nossa parte pessoal também! Pra onde que vai, família, dois filhos, marido... então não tem como levar, é claro que este trabalho não vai sair tão bom, mas nessas condições! (Professora Educação Infantil-5/RM) [...] às vezes a gente até acaba perdendo a paciência com os filhos da gente porque eles querem mexer [...] eles têm aquele interesse de ficar ali perguntando querendo fazer, escrever. Às vezes a gente vai fazer um cartaz eles querem pintar também e às vezes a gente acaba perdendo a paciência ... Tem gente que faz isso [levar trabalho para casa] e eu não faço porque 
se eu for levar para casa eu acabo perdendo a paciência e não sou "dedicadinha", "dedicadinha" não! (Professora Educação Infantil - 6/AF)

Os depoimentos das professoras revelam o conflito instaurado pelas condições de vida e trabalho destas mulheres. Quando priorizam as demandas profissionais sentem-se culpadas pela desatenção e falta de paciência com os filhos. E, ao recusarem-se a utilizar o horário extra-aula para realizar as tarefas profissionais sentem que não estão sendo "dedicadas".

Por outro lado, as afirmações das professoras evidenciam as consequências das condições de trabalho na qualidade do ensino oferecido às crianças, principalmente da educação infantil. Este nível de ensino, historicamente penalizado pela ausência de políticas de investimento e valorização social, continua sendo espaço para improvisações e descaso.

\section{Considerações finais}

A investigação realizada nos permite afirmar que as condições de trabalho nas três redes municipais investigadas apresentam inúmeras dificuldades para as mulheres professoras. Sufocadas pelas demandas familiares, pelas quais são as principais, senão as únicas responsáveis, submetidas a exaustivas jornadas de trabalho, com remuneração insuficiente para poder contratar ajudantes para o trabalho doméstico, debatendo-se para atender às demandas profissionais de melhorar a qualidade do trabalho e elevar o nível da própria formação, essas mulheres estão fazendo um esforço sobre-humano para ensinar nessas condições. E, conforme afirma Esteve (1999, p. 144), "[...] para enfrentar de forma efetiva o mal-estar docente, onde se deve atuar prioritariamente é sobre suas condições de trabalho e sobre o apoio que o professor recebe para realizá-lo".

Considerando que a maioria expressiva do quadro docente é feminina, qualquer medida que se proponha a melhorar a qualidade da educação deve considerar as questões de gênero. Melhores condições de vida e trabalho, inclusive superando-se socialmente a cultura de atribuir às mulheres a responsabilidade pelo cuidado da casa e dos filhos, terão como retorno mulheres mais saudáveis, professoras melhor preparadas, aulas mais adequadas às necessidades das crianças, portanto melhor qualidade de ensino. E, além disso, conforme 
defende Kofi Annan na abertura do documento do UNICEF sobre a situação da infância no mundo, divulgado em 2007:

Eliminar a discriminação de gênero e aumentar o poder da mulher são dois dos principais desafios com que o mundo se depara nos dias atuais. Quando as mulheres são saudáveis, instruídas e livres para aproveitar as oportunidades que a vida lhes oferece, a infância floresce e o país prospera, gerando um duplo dividendo para a mulher e para a criança. (UNICEF, 2007, p. VI)

No caso das professoras não serão apenas os filhos destas mulheres os beneficiados, mas também os alunos e alunas que estão sob a responsabilidade dessas profissionais no início da escolarização.

Entretanto, estas mudanças dependem também da compreensão que as próprias professoras têm das condições em que estão inseridas. É preciso levar estas reflexões para os espaços de formação para que essas mulheres possam compreender e atuar, coletivamente, de maneira a contribuir para a superação das desigualdades de gênero existentes nos ambientes em que vivem e trabalham, ampliando assim as possibilidades de transformação a partir de suas atuações como: sindicalistas, educadoras, formadoras de opinião e produtoras de cultura.

\section{REFERÊNCIAS}

ARAÚJO, T. M. de et al. Diferenciais de gênero no trabalho docente e repercussões sobre a saúde. Ciência e Saúde Coletiva, Rio de Janeiro, v.11, n. 4, p.1117-1129, 2006.

BOURDIEU, P. A dominação masculina. Educação e Realidade, Porto Alegre, v. 20, n. 2, p. 133-184, jul./dez. 1995.

CODO, W. (Coord.) Educação: carinho e trabalho. 4 ed. Petrópolis, RJ.: Vozes/ Brasília, Confederação Nacional dos Trabalhadores em Educação, Universidade de Brasília, Laboratório de Psicologia do Trabalho, 2006. 
ESTEVE, J. M. O mal-estar docente: a sala de aula e a saúde dos professores. Bauru: Edusc, 1999.

GATTI, B. A. Grupo focal na pesquisa em Ciências Sociais e Humanas. Brasília: Líber Livro Editora, 2005.

KOSMINSKY, E. V.; SANTANA, J. N. Crianças e jovens e o trabalho doméstico: A construção social do feminino. Sociedade e Cultura, Goiânia, v. 9, n. 2, p. 227-236, jul./dez., 2006. Disponível em: <http://www.revistas.ufg.br/index.php/ fchf/issue/view/403>. Acesso em: 31/01/2008.

MARCONDES, W. B. et al. O peso do trabalho "leve" feminino à saúde. Perspectiva, São Paulo, v. 17, n. 2, p. 91-101, abr./jun. 2003. Disponível em: $<$ http://www.scielo.br/scielo.php?script $=$ sci_arttext\&pid=S010283920030002 00010\&lng=pt\&nrm=iso $>$. Acesso em: 31/01/2008.

MAUÉS, O. As políticas de formação de professores: A universitarização e a prática. In: REUNIÃO ANUAL DA ANPED, 26., 2003, Poços de Caldas-MG.

SCOTT, J. Gênero: uma categoria útil de análise histórica. Educação e Realidade, Porto Alegre, v. 20, n. 2, p. 71-99, jul./dez. 1995.

SIQUEIRA, M. J. T.; FERREIRA, E. S. Saúde das professoras das Séries Iniciais: o que o gênero tem a ver com isso? Psicologia Ciência e Profissão, Brasília, v. 23, n. 3, p. 76-83, 2003.

SORJ, B. Trabalho e responsabilidades familiares: Um estudo sobre o Brasil. Relatório final. Universidade Federal do Rio de Janeiro. Rio de Janeiro, 2004. Disponível em <http://www.cfemea.org.br/temasedados/detalhes. asp?IDTemasDados=129>. Acesso em: 31/03/2008.

UNESCO. O perfil dos professores brasileiros - o que fazem, o que pensam, o que almejam... São Paulo: Editora Moderna/Instituto Paulo Montenegro/INEP/ MEC, 2004.

UNICEF. Situação mundial da infância 2007: Mulheres e crianças - O duplo dividendo da igualdade de gênero. Brasília: Escritório da Representante do UNICEF no Brasil, 2007.

VASQUES-MENEZES, I.; CODO, W.; MEDEIROS, L. O conflito entre o trabalho e a família e o sofrimento psíquico. In: CODO, W. (Coord.). Educação: carinho e trabalho. 4. ed. Petrópolis: Vozes; Brasília: Confederação Nacional 
dos Trabalhadores em Educação: Universidade de Brasília. Laboratório de Psicologia do Trabalho, 2006. p. 255-260.

VENTURI, G.; RECAMÁN, M. As mulheres brasileiras no início do século 21. Relatório direitos Humanos no Brasil, 2005. Disponível em: $<\mathrm{http}: / / \mathrm{www} 2$. fpa.org.br/portal $/$ modules $/$ news $/$ index.php?storytopic $=101 \&$ start $=40>$. Acesso em: 02/04/2008.

Texto recebido em 01 de agosto de 2009.

Texto aprovado em 20 de setembro de 2009. 